REF - ISSก 1888-8884 Vol. IV [2], 288-228, 2887

\title{
AVALIAÇÃO DA COMPOSIÇÃO QUÍMICA E ATIVIDADE ANTIBACTERIANA DOS ÓLEOS ESSENCIAIS DE Aloysia gratissima (Gillies \& Hook) Tronc. (ALFAZEMA), Ocimum gratissimum L. (ALFAVACA-CRAVO) E Curcuma longa L. (AÇAFRÃO)
}

\author{
EVALUATION OF THE CHEMICAL COMPOSITION AND ANTIBACTERIAL ACTIVITY OF \\ ESSENTIAL OILS OF Aloysia gratissima (Gillies \& Hook) Tronc., Ocimum gratissimum L. \\ AND Curcuma longa $L$. \\ Ana L. P. Franco ${ }^{1}$; Tiago B. Oliveira ${ }^{1,2}$; Pedro H. Ferri ${ }^{3}$; Maria Teresa F. Bara ${ }^{1}$; \\ José Realino de Paula ${ }^{*}$ \\ ${ }^{1}$ Laboratório de Farmacognosia, Faculdade de Farmácia, Universidade Federal de Goiás. Praça Universitária s/n. \\ 74605-220. Goiânia-GO, Brasil. \\ ${ }^{2}$ Centro Universitário de Anápolis - UniEvangélica. \\ ${ }^{3}$ Instituto de Química/UFG.
}

* Autor para correspondência. E-mail: pjrpaula@bol.com.br

Recebido em 10/11/2007 - Aceito em 12/12/2007

RESUMO: A busca de moléculas antimicrobianas naturais presentes em plantas tem sido alvo de diversos estudos científicos. Os óleos essenciais da Aloysia gratissima (Gillies \& Hook) Tronc. (alfazema), Ocimum gratissimum L. (alfavaca-cravo) e Curcuma longa L. (açafrão) foram extraídos por hidrodestilação em aparelho de Clevenger modificado e analisados quanto à composição química e atividade antibacteriana. $A$ análise da composição química foi realizada por CG/EM e atividade antibacteriana foi avaliada pelo método da difusão em ágar com os microrganismos Staphylococcus aureus ATCC 6538, Salmonella choleraeseus ATCC 10708 e Escherichia coli O:158. Para alfavaca-cravo, empregou-se também a bioautografia em CCD para avaliar a atividade antibacteriana. Dentre as amostras estudadas, a alfavaca-cravo foi a única ativa contra todas as cepas. O crescimento de Staphylococcus aureus ATCC 6538 foi inibido pelos três óleos essenciais estudados. Nos experimentos de bioautografia verificou-se que o eugenol foi o principal componente bioativo no óleo essencial de Ocimum gratissimum L.

PALAVRAS-CHAVE: antibacterianos, cromatografia gasosa, eugenol.

ABSTRACT: The discovery of antimicrobial natural substances demonstrated for plants has been the target of several scientific studies. The essential oils of the Aloysia gratissima (Gillies \& Hook) Tronc., Ocimum gratissimum L. and Curcuma longa L. was extracted by steam-distillation using a Clevenger modified apparatus and were analyzed to the chemical composition and antibacterial activity. The analysis of the chemical composition was carried out by GC/MS and antibacterial activity was evaluated by agar diffusion with the microorganisms Staphylococcus aureus ATCC 6538, Salmonella choleraeseus ATCC 10708 and Escherichia coli 0:158. The antibacterial activity of the essential oil of Ocimum gratissimum L., was evaluated by bioautography. Among the studied samples, Ocimum gratissimum L. was the only active against all strains. The growth of Staphylococcus aureus ATCC 6538 was inhibited by the three studied essential oil. For the bioautography experiments it was verified that eugenol was the main bioactive component in the essential oil of Ocimum gratissimum L.

KEYWORDS: anti-bacterial, gas chromatography, eugenol. 


\section{INTRODUÇÃO}

Nas últimas décadas observa-se um grande interesse pelo potencial terapêutico das plantas medicinais (YUNES et al, 2001). Tal fato é comprovado pela evidência de que hoje, cerca de $30 \%$ das drogas prescritas no mundo são obtidas direta ou indiretamente de plantas. Além disso, cerca 50\% das drogas desenvolvidas entre 1981 e 2002 foram obtidos a partir de produtos naturais, ou análogos semi-sintéticos ou ainda compostos sintéticos baseados em produtos naturais (KOEHN \& CARTER, 2005).

Tem-se verificado um grande avanço científico envolvendo os estudos químicos e farmacológicos de plantas medicinais que visam obter novos compostos com propriedades farmacêuticas (CECHINEL \& YUNES, 1998). Dentre estes compostos se destacam os constituintes químicos existentes nos óleos essenciais das plantas, pois pertencem ao maior e mais diversificado grupo dentro dos produtos naturais e por apresentarem uma grande importância terapêutica e econômica (SILVA et al, 2003b).

Deve-se destacar que a composição dos óleos essenciais é determinada por fatores genéticos, porém os fatores ambientais podem causar variações significativas em seus componentes. A época da colheita, fontes geográficas, o horário, o modo de secagem do material vegetal e fatores ambientais, como umidade, água, solo e herbivoria também podem influenciar sobre a composição e o teor do óleo (SANTOS et al., 2004; SILVA et al., 2003a; SILVA et al, 2003b, GOBBO-NETO \& LOPES, 2007) e com isso aumentar ou diminuir a resposta biológica (SANTOS et al, 2004; BURT, 2004).

A utilização de substâncias antibióticas ou antimicrobianas representa talvez um dos maiores avanços da farmacoterapia. Estas substâncias estão entre os fármacos mais utilizados, tanto em ambulatórios quanto em hospitais e têm reduzido drasticamente a incidência de muitas doenças infecciosas. Por outro lado, muitas infecções causadas por microrganismos emergentes ou multirresistentes permanecem sem opções terapêuticas efetivas, aliado aos sérios efeitos colaterais produzidos pela farmacoterapia (TAVARES, 2001; HARDMAN et al., 2003)

A investigação de moléculas antimicrobianas naturais presentes em plantas tem sido alvo de diversos estudos científicos (SILVA et al, 2003b; ADAMU et al, 2005; AMARAL \& BARA, 2005; PAULA et al, 2006; DUARTE et al, 2007; JIROVETZ et al, 2007) e os dados obtidos são muito promissores na busca de novas substâncias bioativas.

\section{Características botânicas das espécies estudadas}

Aloysia gratissima (Gillies \& Hook) Tronc. (alfazema do Brasil)

Apresenta-se como um arbusto que alcança uma altura máxima de 3 metros. Ocorre como touceiras densas e desordenadas contendo espinhos nos ramos (Figura 1A e 1B). Possui flores de coloração branca, dispostas em cachos ao longo dos ramos, muito perfumadas, florescendo na primavera e verão. Segundo CORDO \& DELOACH (1995) o gênero Aloysia da família Verbenaceae é provavelmente originário da América do Sul tendo como centro de distribuição a Argentina. No Brasil a espécie Aloysia gratissima (Gillies \& Hook) Tronc. é comumente cultivada como ornamental, sendo conhecida como Alfazema do Brasil por ser uma


Figura 1: Aloysia gratissima (Gillies \& Hook) Tronc. Cultivada no Horto de Plantas Medicinais de FF/UFG. A - Aspecto geral da touceira; B - Aspecto dos ramos.

planta bastante aromática com odor que assemelha ao da Alfazema (Lavandula officinalis Chaix \& Kitt).

\section{Ocimum gratissimum L. (alfavaca-cravo)}

O nome alfavaca caracteriza várias plantas do mesmo gênero, muito semelhantes entre si. Porém esta é facilmente reconhecida pelo aroma que lembra o cravo-da-índia (Eugenia caryophyllata Thumb). Possui as flores e frutículos dispostos em numerosas inflorescências eretas típicas do gênero. 
Produz numerosas sementes que germinam facilmente (MATOS, 2000).

Esta planta é originária da Ásia tropical e é subespontânea em todo o Brasil. É uma planta arbustiva, aromática, que atinge de $40 \mathrm{~cm}$ a $1 \mathrm{~m}$ de altura (Figura 2). Adapta-se melhor às regiões de clima quente. Foi introduzida no Brasil pela colônia italiana, que a utiliza como tempero em massas, molhos e carnes (MATOS, 2000).

Curcuma longa L. (açafrão do Brasil)

O açafrão ou cúrcuma, como também é conhecido, é considerado uma especiaria preciosa (MATOS, 2000). Morfologicamente caracteriza-se como uma pequena erva aromática, anual, composta de um rizoma principal com várias ramificações menores, todas marcadas com anéis de brácteas secas (Figura 3). Cada rizoma mede até $10 \mathrm{~cm}$ de comprimento e quando cortados mostram uma superfície de cor vermelha alaranjada, proveniente da presença do pigmento curcumina (I). Possui cheiro forte agradável e sabor aromático e picante. Originária da Índia, mas é muito cultivada nos países tropicais como planta medicinal ou condimentar (MATOS, 2000).

O açafrão é conhecido no mercado internacional como "turmeric", tendo sua importância econômica devida às peculiares características de seus rizomas, podendo ser usado como uma alternativa natural para substituição de pigmentos sintéticos, princi palmente na área alimentícia e talvez futura mente até como antioxidante na fabricação desses produtos (CECILIO FILHO et al, 2000).

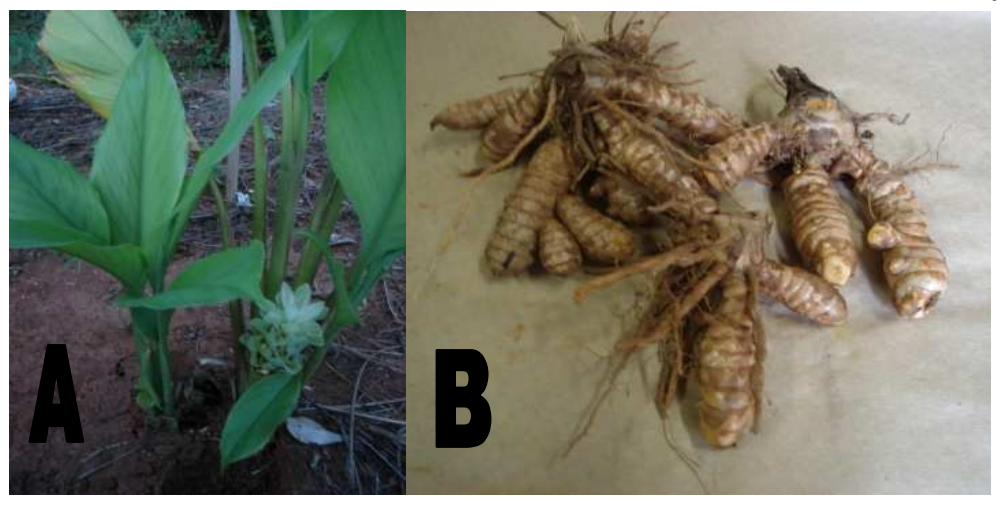

Figura 3: Curcuma longa L. cultivado no Horto de Plantas Medicinais da FF/UFG. A - Aspecto geral das partes aéreas; B - Aspecto geral dos rizomas.

\section{Atividades farmacológicas e princípios ativos das espécies estudadas}

\section{Aloysia gratissima (Gillies \& Hook) Tronc. (alfazema do Brasil)}

Estudos sobre Aloysia gratissima (Gillies \& Hook) Tronc. concentram na análise do óleo essencial visando o seu uso na indústria de perfume. A planta medicinal mais estudada no gênero é Aloysia triphylla (L'Hérit.) Britt. originária da América do Sul e cultivada no Norte da África (Marrocos) e Sul da Europa, onde o chá das folhas é bastante utilizado pela população destas áreas devido suas propriedades aromáticas, digestivas e antiespasmódicas (CARNOT et al, 1999). Os principais componentes do óleo essencial de $A$. triphylla são citral, neral, geranial, limoneno, 1,8-cineol, geraniol e beta-cariofileno (CARNOT et al., 1999; PÉREZ et al., 1998). PÉREZ et al, 1998 verificaram a atividade antidiarréica do óleo essencial de $A$. triphylla em testes sobre a diarréia induzida em camundongos por óleo de rícino ou sulfato de magnésio.

SOLER et al (1986) verificaram que o óleo essencial de Aloysia gratissima (Gillies \& Hook) Tronc. apresenta mais de $70 \%$ de hidrocarbonetos, dos quais mais da metade são sesquiterpenos, sendo o principal deles o sabineno (II) $(30 \%)$ seguido do $\beta$-pineno (III) (8\%). Constituintes oxigenados são principalmente cetonas e álcoois sesquiterpênicos, sendo os monoterpenos oxigenados menos do que $6 \%$. 

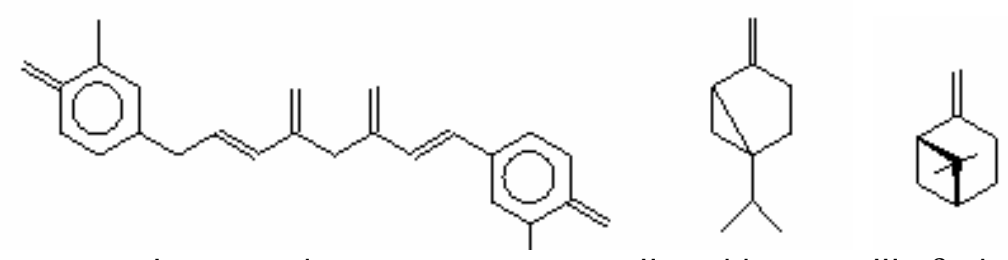

I - curcumina

II - sabineno III - $\beta$-pineno<smiles>C=CCc1ccc(O)c(OC)c1</smiles>

IV - eugenol<smiles>CC12CCC(CC1)C(C)(C)O2</smiles>

$\mathrm{V}$ - 1,8-cineol<smiles>C=CCc1ccc(OC)cc1</smiles>

VI - estragol<smiles>C=CC(O)c1ccc(OC)cc1</smiles>

VII - 1-hidroxiestragol

\section{Ocimum gratissimum L. (alfavaca-cravo)}

Toda a parte aérea da planta contém óleo essencial rico em eugenol (IV), seu princípio ativo responsável pela atividade antimicrobiana, cujo teor é maior por volta de $12.00 \mathrm{~h}$; período em que deve ser feita a coleta para uso como anti-séptico local. Neste período o teor de eugenol (IV) pode atingir até 98\%, sendo que às 17:00 h esse teor pode ser $11 \%$, uma vez que o teor de eugenol presente no óleo essencial de alfavaca sofre variações de acordo com a influência de a luz solar (SILVA et al, 1999). No início da manhã e final da tarde ocorre um predomínio de 1,8-cineol (V), princípio balsâmico, o que justifica o uso popular da planta em preparações antigripais quando a coleta for realizada neste horário (MATOS, 2000).

LIMA (1992) descreve que o óleo essencial do Ocimum gratissimum L., apresenta potente atividade antifúngica sobre alguns dermatófitos isolados de pacientes com dermatofitoses, sendo esta atividade equivalente ao cetoconazol. FARIA et al (2006) descreve que o óleo essencial inibe o crescimento de fitopatogênicos Botryosphaeria rhodina e duas espécies de Alternaria sp., Alternaria isolada de tomate (A1) e Penicillium chrysogenum.

DUBEY et al. (2000) relataram o uso de Ocimum gratissimum L., na medicina popular como estomáquico e antipirético e verificaram que um quimiotipo de Ocimum gratissimum L. cultivado na Índia apresenta altos níveis de cinamato etila (34\%), linalol (30\%) e cineol (6,5\%). O óleo essencial das folhas das plantas deste quimiotipo apresentou um interessante espectro de atividade antifúngica sobre vários fungos como Candida albicans, Cryptococcus neoformans, Trichophyton rubrum, Trichophyton mentagrophytes, Trichophyton interdigitale e outros.

ORAFIDIYA et al (2001) descreveram a atividade antibacteriana do óleo essencial de Ocimum gratissimum L. sobre Staphylococcus aureus, Pseudomonas aeruginosa e Proteus spp. NAKAMURA et al. (1999) detectaram a atividade do referido óleo essencial sobre Proteus mirabilis, Klebsiella sp, Escherichia coli, Salmonella enteritidis, Staphylococcus aureus e Shigella flexineri.

AGUIYI et al (2000) descreveram a atividade hipoglicemiante do extrato metanólico das folhas de Ocimum gratissimum L. em ratos wistar machos normais e com diabetes induzida por aloxano. $\mathrm{Na}$ dose de $400 \mathrm{mg} / \mathrm{kg}$ intraperitoneal o referido extrato reduziu os níveis de glicose no sangue de $56 \%$ nos ratos normais e de $69 \%$ nos diabéticos.

OFFIAH \& CHIKWENDU (1999) demonstraram uma atividade antidiarréica do extrato aquoso das folhas de Ocimum gratissimum L. padronizado em $78,3 \mathrm{mg} / \mathrm{mL}$ de resíduo sólido, sobre a diarréia induzida por óleo de rícino em ratos albinos nas doses 10 e $20 \mathrm{~mL} / \mathrm{kg}$. No íleo isolado de cobaio o extrato reduziu as respostas do íleo à acetilcolina, nicotina e histamina. Isto sugere que o efeito antidiarréico ocorre pela diminuição da motilidade intestinal via inibição de receptores muscarínicos.

KÉITA et al (2001) demonstraram a atividade inseticida do óleo essencial de Ocimum gratissimum L. e O. basilicum aplicados por fumigamento ou em pó de kaolin sobre o besouro Callosobruchus maculatus que ataca sementes armazenadas.

AYISI \& NYADEDZOR (2003) detectaram atividade antiviral do extrato aquosa das folhas de Ocimum gratissimum sobre os vírus do HIV-I e HIV-2 em ensaios in vitro. UEDA-NAKAMURA et al (2006) demonstraram a 
atividade leishmanicida do óleo essencial das folhas de Ocimum gratissimum e de seu principal constituinte, o eugenol, sobre Leishmania amazonensis em ensaios in vitro.

Alguns acessos de Ocimum gratissimum L. podem apresentar até $1 \%$ de estragol (VI) no óleo essencial (VIEIRA et al, 2001). Existem estudos que descrevem os derivados alilbenzenos como estragol (VI), metileugenol e safrol como hepatocarcinogênicos em roedores em doses altas (CHAN \& CALDWELL, 1992). Os alilbenzenos por si só não são hepatotóxicos e nem hepatocarcinogênicos, mas sim os seus metabólitos 1-hidroxi derivados, como o 1hidroxiestragol (VII). O estragol (VI) está presente no óleo essencial de várias plantas como as do gênero Ocimum, as quais, são utilizadas como condimentos e flavorizantes na preparação de alimentos. De acordo com VINCENZI et al (2000) o estragol (IV) é um carcinogênico e genotóxico natural, demonstrado em experimentos com animais de laboratórios após exposição crônica ou poucas doses repetidas. O 1-hidroxiestragol (VII) é o suposto metabólito responsável pela sua ação carcinogênica. O 1-hidroxiestragol já foi encontrado na urina de seres humanos submetidos a ensaios clínicos com doses de $100 \mu \mathrm{g} /$ dia de estragol durante 6 meses, onde a excreção urinária do primeiro foi de aproximadamente $0,3 \%$ (VINCENZI et al, 2000). Existe a necessidade de melhores estudos sobre a ação carcinogênica do estragol em ratos e camundongos, enquanto isso, a presença de estragol em alimentos não deve ultrapassar $0,05 \mathrm{mg} / \mathrm{kg}$ (VINCENZI et al, 2000). Mediante o exposto, observa-se a necessidade de análise da presença de estragol no óleo essencial de amostras de plantas do gênero Ocimum que serão empregados no preparo de fitoterápicos de uso interno.

\section{Curcuma longa L. (açafrão do Brasil)}

MATOS (1997), HE et al (1998) e SOUZA \& GLORIA (1998) relataram que os principais componentes de interesse do açafrão são o óleo essencial e uma substância corante avermelhada, a curcumina (I), que, de acordo com KUMAR et al. (1998), aumenta a excreção do colesterol e ácidos biliares sendo, por isso, útil no tratamento da prisão de ventre habitual e como auxiliar na digestão.

CHATTERJEE et al (1999), KHAR et al (1999), SINGHAL et al (1999), BHAUMIK et al (2000) e CHUANG et al (2000) mostraram em seus experimentos que a curcumina inibe a carcinogênese, sendo que KHAR et al (1999) sugere que esta atividade anticancerígena seja principalmente devido a habilidade de indução da apoptose - morte celular programada - em células tumorais. BHAUMIK et al (2000) propuseram duas possibilidades para o efeito da curcumina sobre células tumorais, uma direta através da indução da apoptose e outra secundária através da ativação de células do sistema imune.

RAMÍREZ-BOSCÁ et al (2000), descreveram o uso da curcumina (I) como um agente antiaterogênico, devido à capacidade de aumentar o HDL e diminuir os valores do LDL. KUMAR et al (1998) analisaram o Lipotab Forte, uma formulação fitoterápica polifarmacêutica, que contém Curcuma longa L., usado no tratamento da aterosclerose, que é responsável por uma queda na peroxidação dos lipídeos inibindo assim a aterogênese. Correlacionado a esta atividade, pode-se dizer que ocorre também uma resistência na oxidação do LDL (RAMÍREZ-TORTOSA, 1999), podendo então, ser usado no tratamento de numerosas doenças cardiovasculares na qual a aterosclerose tem maior função.

Conforme BOSCÁ et al (2000), um extrato hidroalcoólico de Curcuma longa L., abaixa níveis altos de fibrinogênio no plasma humano, porém sem alteração significativa na coagulação sanguínea, em contrapartida LEE (2006) sugere que o ar-turmerone isolado de Curcuma longa L. inibe a agregação plaquetária induzida por colágeno e ácido araquidônico.

APISARIYAKUL et al (1995), compararam o óleo essencial com a curcumina em alguns fungos e verificaram atividade antifúngica do óleo em dermatófitos, porém não exerceu nenhuma atividade sobre as leveduras, e a curcumina não apresentou nenhuma atividade antifúngica.

KHAR et al (1999) relataram que a curcumina apresenta atividades antimutagênica e anticarcinogênica em adição à atividade antiinflamatória. Segundo NADKARNI (1976), KUTTAN (1985), SHARMA (1976) e RAMPRASAD (1956) citados por BHAUMIK et al (2000) a curcumina, o componente ativo do rizoma da Curcuma longa L. possui um largo espectro de aplicação terapêutica como antiinflamatório, antioxidante, bactericida, efeito anti-helmíntico e auxiliar na redução do nível de colesterol.

Conforme citado por CECILIO FILHO et al (2000) além do principal uso da cúrcuma como condimento, possui substâncias antioxidantes, antimicrobianas e corantes (curcumina) que the conferem possibilidade de emprego nas áreas de cosméticos, têxtil, medicinal e alimentício.

$\mathrm{XIA}$ et al (2007) analisaram os efeitos neuroquímico e neuroendócrino de extrato etanólico de Curcuma longa L. em ratos e verificaram que o extrato pode ter ação antidepressiva mediada por estes efeitos.

Este trabalho apresenta um estudo da composição química e atividade antibacteriana dos óleos essenciais de Aloysia gratissima (Gillies \& Hook) Tronc. (alfazema do Brasil), Ocimum gratissimum L. (alfavaca-cravo) e Curcuma longa L. (açafrão do Brasil) sobre algumas cepas de bactérias investigadas através das metodologias de difusão em ágar por impregnação em disco de papel de filtro e por meio da bioautografia em CCD. 


\section{METODOLOGIA}

\section{Material botânico}

Aloysia gratissima (Gillies \& Hook) Tronc (alfazema do Brasil): as folhas foram colhidas no Horto de Plantas Medicinais da FF/UFG (Goiânia - GO, 16 40' 33,3" sul, 49 14' 39,5" oeste, 768 m altitude) em março de 2000. Dessecadas à temperatura ambiente e trituradas em moinho de facas até a forma de pó. Em julho de 2000 foi realizada a extração do óleo essencial. Uma exsicata foi depositada no Herbário da Universidade Federal de Goiás sob o número UFG-22395.

Ocimum gratissimum L. (alfavaca-cravo): as folhas foram colhidas no Horto de Plantas Medicinais da FF/UFG em fevereiro de 2001, por volta das 9:00 h da manhã, fragmentadas com tesoura, e o material fresco foi utilizado para extração do óleo essencial. Uma exsicata foi depositada no Herbário da Universidade Federal de Goiás sob o número UFG-27157.

Curcuma longa L. (açafrão do Brasil): os rizomas foram colhidos no Horto de Plantas Medicinais da FF/UFG em julho de 1998, fragmentados com faca e o material fresco utilizado para extração do óleo essencial.

\section{Extração dos óleos essenciais}

As amostras de óleos essenciais foram extraídas por hidrodestilação em aparelho de Clevenger modificado por 4 a 5 horas. Os óleos essenciais obtidos foram acondicionados em frascos de vidro e armazenados em freezer a $10^{\circ} \mathrm{C}$ até serem usados.

\section{Avaliação da atividade antibacteriana}

Microrganismos usados

Os ensaios biológicos foram realizados utilizando os seguintes microrganismos: Staphylococcus aureus ATCC 6538; Salmonella choleraeseus ATCC 10708 e Escherichia coli O:158, sendo este último isolado de fezes diarréicas de crianças, pelo Laboratório de Bacteriologia do IPTSP/UFG.

Avaliação da atividade antibacteriana pelo método da difusão em ágar

Os microrganismos conservados em ágar casoy foram ativados em caldo casoy por 24 horas a $37^{\circ} \mathrm{C}$ e então, as cepas gram-negativas e gram-positivas foram semeadas em ágar MacConkey e ágar sal manitol, respectivamente. Novamente incubou a $3^{\circ} \mathrm{C}$ por um período de 24 horas e, a partir das culturas, fez-se uma suspensão de bactérias em solução salina, de acordo com o tubo $\mathrm{n}^{\circ} 1$ da escala de Mc Farland, o qual possui um número aproximado de $3,0.10^{8}$ bactérias $/ \mathrm{mL}$, sendo que $2 \mathrm{~mL}$ desta suspensão foi incorporada a $20 \mathrm{~mL}$ de ágar Mueller Hinton a $40^{\circ} \mathrm{C}$ homogeneizado e vertido em placas de petri estéreis. Após solidificação, acrescentou-se discos de papel de filtro de $6 \mathrm{~mm}$ de diâmetro (Discos Blank estéreis/ CECON) impregnados com $5 \mu \mathrm{L}$ de cada óleo essencial em estudo e um disco de cloranfenicol 30 $\mathrm{gg}$ (Sensibiodisc/CECON) como controle positivo.

Após a incubação por um período de 24 horas a $3^{\circ} \mathrm{C}$, fez-se aplicação por nebulização do corante TTC (cloreto de 2,3,5 trifeniltetrazólio, $20 \mathrm{mg} / \mathrm{mL}$ em água) para tornar mais evidente o halo de inibição formado, sendo que nos locais onde houve crescimento bacteriano adquire uma coloração lilás e rosa claro no local (zona) em que o crescimento do microrganismo foi inibido (HAMBURGER \& CORDELL, 1987). O halo de inibição foi medido com paquímetro. $\mathrm{O}$ experimento foi feito em duplicata.

Avaliação da atividade antibacteriana por bioautografia em CCD

Aplicou-se $5 \mu \mathrm{L}$ do óleo essencial de Ocimum gratissimum L. (alfavaca-cravo) e de eugenol (Sigma), ambos dissolvidos em $\mathrm{CH}_{2} \mathrm{Cl}_{2}$, na proporção de $10 \mu \mathrm{L}$ para $1 \mathrm{~mL}$ de solução em uma placa cromatográfica com sílica $(5 \mathrm{~cm}$ de largura x 6,5 cm de comprimento), utilizando $\mathrm{CH}_{2} \mathrm{Cl}_{2}$ como fase móvel. Após eluição, colocou-se a placa, esterilizada previamente em radiação UV, em uma placa de petri, que continha $10 \mathrm{~mL}$ de ágar Mueller Hinton solidificado. Adicionou sobre a mesma, para revelação, uma suspensão de microrganismos (20mL de ágar Mueller Hinton a $40^{\circ} \mathrm{C}$ e $1 \mathrm{~mL}$ da suspensão de cada bactéria, individualmente, em salina correspondente ao tubo no 1 da Escala de Mc Farland $-3 \times 10^{8}$ bactérias $/ \mathrm{mL}$ ). Após solidificação do meio de cultura, incubou-se a $37^{\circ} \mathrm{C}$ por 24 horas. Para melhor 
contrastar o possível halo de inibição do crescimento bacteriano, nebulizou-se o corante TTC, preparado na concentração de 20mg/mL em água (HAMBURGER \& CORDELL, 1987; SAXENA et al, 1995).

\section{Avaliação da composição química dos óleos essenciais estudados}

As amostras dos óleos essenciais obtidos foram submetidas a uma análise por cromatografia gasosa acoplada a espectrometria de massas (CG/EM) no aparelho Shimadzu QP5050A utilizando uma coluna capilar de sílica fundida (CBP-5; 30m $\times 0,25 \mathrm{~mm} \times 0,25 \mu \mathrm{m})$, mantendo-se um fluxo de $1 \mathrm{~mL} / \mathrm{min}^{-1}$ de Hélio, como gás de arraste, e aquecimento com temperatura programada $\left(60^{\circ} \mathrm{C} / 2 \mathrm{~min} ; 3^{\circ} \mathrm{C} \cdot \mathrm{min}^{-1} / 240^{\circ}, 10^{\circ} \mathrm{C} \cdot \mathrm{min}^{-1} ; 280^{\circ} \mathrm{C} / 10 \mathrm{~min}\right)$, e a energia de ionização de $70 \mathrm{eV}$. Volume de injeção de $1 \mu \mathrm{L}$ das amostras diluídas em $\mathrm{CH}_{2} \mathrm{Cl}_{2}(20 \% \mathrm{p} / \mathrm{v})$ no modo Split com uma razão de 1:50. Identificação dos componentes dos óleos essenciais foi realizada por comparação dos espectros de massa e índices de retenção com os valores de literatura dos componentes mais comuns de óleos essenciais (ADAMS, 2007). Os índices de retenção foram calculados através da coinjeção de uma mistura de hidrocarbonetos, C8 - C32, e com aplicação da equação de Van Den Dool e Kratz (DOOL \& KRATZ, 1963; ADAMS, 2007).

\section{RESULTADOS E DISCUSSÃO}

\section{Avaliação da atividade antibacteriana dos óleos essenciais pelo método da difusão em ágar}

Os valores dos halos de inibição $(\mathrm{mm})$ do crescimento bacteriano observados para os óleos essenciais frente a S. aureus ATCC 6538, E. coli O:158 e S. choleraeseus ATCC 10708 estão apresentados na Tabela 1. Discos

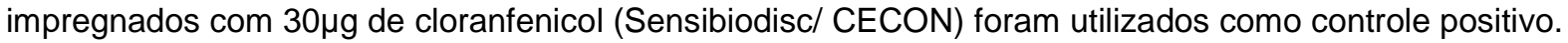

De acordo com os resultados, pode-se observar que o óleo essencial de Aloysia gratissima (Gillies \& Hook) Tronc. apresentou atividade antimicrobiana sobre o $S$. aureus ATCC 6538, equivalente ao cloranfenicol, e não apresentou nenhuma atividade sobre as demais cepas. Pode-se sugerir uma atividade antibacteriana de menor espectro de ação atuando apenas sobre um microrganismo gram-positivo.

O óleo essencial de Curcuma longa L. apresentou uma atividade antibacteriana sobre o S. aureus ATCC 6538 superior ao cloranfenicol, porém não apresentou nenhuma atividade sobre os demais microrganismos, podendo também ser sugerido uma atividade antibacteriana específica para bactérias gram-positivas;

O óleo essencial de Ocimum gratissimum L. possui atividade inibidora do crescimento de todas as cepas avaliadas, provavelmente devido à presença de eugenol (57\%) como componente majoritário, embora não se deve descartar a possibilidade de sinergismo entre os demais componentes do óleo essencial, mesmo que presentes em menores concentrações.

Tabela 1: Atividade antibacteriana dos óleos essenciais de O. gratissimum L., A. gratissima (Gill \& Hook) e $C$. longa L. frente a diferentes microrganismos.

ÓLEOS ESSENCIAIS

S. aureus ATCC 6538
E. coli $0: 158$

S. choleraeseus

ATCC 10708
Ocimum gratissimum L. (alfavaca-cravo)

22

12

Curcuma longa L. (açafrão do Brasil)
10

10
25

20 (alfazema do Brasil)

Cloranfenicol

Os valores representam o diâmetro do halo de inibição $(\mathrm{mm})$;
30

30 
Estudos adicionais com os óleos que apresentaram atividade apenas sobre o S. aureus ATCC 6538 são interessantes, para investigar ação específica sobre bactérias gram-positivas.

Avaliação da atividade antibacteriana por bioautografia em CCD

A bioautografia é uma técnica utilizada para a detecção de substâncias antimicrobianas sobre um microrganismo específico inoculado em um recipiente específico com meio de cultura adequado distribuído sobre uma placa de cromatografia em camada delgada (CCD) após eluição da mistura a ser avaliada em eluente específico (BETINA, 1973; LUND \& LYON, 1975; DIDRY et al, 1990; SAXENA et al, 1995).

Nos ensaios bioautográficos realizados com o óleo essencial de Ocimum gratissimum L. (alfavaca-cravo), observou-se inibição das três bactérias avaliadas, com formação de halos de inibição nas manchas correspondentes ao eugenol, $R_{f}$ cerca de 0,72 , da amostra e da substância padrão. Esta observação corrobora com a hipótese de que atividade antibacteriana do óleo essencial de Ocimum gratissimum L. se deve ao seu conteúdo em eugenol.

A atividade inibidora do crescimento de microrganismos pelo eugenol presente em plantas medicinais tem sido relatado na literatura (BARA \& VANETTI, 1995; DE et al, 1999; GAYOSO et al, 2005; FARIA et al, 2006). Outras atividades biológicas, tais como atividade anti-viral (BENENCIA \& COURRĖGES, 2000), anti-helmíntica (ASHA et al, 2001) e anti-leishmania (UEDA-NAKAMURA et al, 2006) são descritas para o eugenol.

\section{Avaliação da composição química dos óleos essenciais}

A Tabela 2 apresenta os resultados da análise da composição química dos óleos essenciais obtidos por hidrodestilação, em aparelho de clevenger modificado, das folhas de Aloysia gratissima (Gillies \& Hook) Tronc., Ocimum gratissimum L. e rizomas de Curcuma longa L., bem como, o rendimento no processo de extração.

$\mathrm{Na}$ análise da composição química observou-se um alto teor de $\beta$-pineno $(14,06 \%)$, trans-pinocanfona $(18,42 \%)$ e acetato de trans-pinocarvila (13,55\%) no óleo de Aloysia gratissima (Gill \& Hook) Tronc. Ocimum gratissimum L. observou um predomínio de eugenol (57,82\%), $\gamma$-terpineno (13,06\%) e $\alpha$-bisaboleno (17,19\%). A ausência de estragol (metilchavicol) no óleo essencial de Ocimum gratissimum L. cultivada no Horto de Plantas Medicinais da FF/UFG e coletada nesta época permite sugerir que este quimiotipo pode ser utilizado na preparação de fitoterápicos após a realização de estudos de sazonalidade (GOBBO-NETO \& LOPES, 2007). No óleo essencial de Curcuma longa L. observou a presença de turmerona $(28,6 \%)$ e $\gamma$-z-atlantona $(26,10 \%)$ como componentes majoritários.

Tabela 2: Principais componentes (\%) dos óleos essenciais de A. gratissima, O. gratissimum e C. longa.

\begin{tabular}{|c|c|c|c|}
\hline Componentes & Aloysia gratissima $^{a}$ & Ocimum gratissimum ${ }^{b}$ & Curcuma longa $^{c}$ \\
\hline Tricicleno & & 0,30 & \\
\hline$\alpha$-pineno & 1,43 & & \\
\hline Sabineno & 0,44 & & \\
\hline$\beta$-pineno & 14,06 & & \\
\hline Mirceno & 1,99 & 0,34 & \\
\hline$\alpha$-felandreno & & & 2,27 \\
\hline$\alpha$-terpineno & & 0,30 & \\
\hline p-cimeno & & 2,11 & 1,24 \\
\hline Limoneno & 2,29 & & \\
\hline 1,8-cineol & & & 4,76 \\
\hline$\beta$-ocimeno & & 0,49 & \\
\hline$\gamma$-terpineno & & 13,06 & \\
\hline Terpinoleno & & & 0,47 \\
\hline p-cimeneno & & 0,26 & \\
\hline Linalool & 1,83 & & \\
\hline
\end{tabular}




\begin{tabular}{|c|c|c|c|}
\hline Trans-pinocarveol & 3,41 & & \\
\hline Cis-verbenol & 1,48 & & \\
\hline Trans-pinocanfona & 18,42 & & \\
\hline Pinocarvona & 2,08 & & \\
\hline Pinocanfona & 6,59 & & \\
\hline 4-terpineol & & 0,24 & \\
\hline Mirtenal & 1,28 & & \\
\hline Mirtenol & 1,84 & & \\
\hline Acetato de bornila & 0,71 & & \\
\hline Timol & & 9,80 & \\
\hline $\begin{array}{l}\text { Acetato de trans- } \\
\text { pinocarvila }\end{array}$ & 13,55 & & \\
\hline Carvacrol & & 0,28 & \\
\hline Eugenol & & 57,82 & \\
\hline$\alpha$-copaeno & & 0,11 & \\
\hline$\beta$-elemeno & 0,51 & & \\
\hline$\beta$-cariofileno & 4,99 & 3,03 & \\
\hline$\gamma$-elemeno & 1,15 & & \\
\hline$\alpha$-humuleno & 1,41 & 0,31 & \\
\hline$\beta$-E-farneseno & & 0,39 & \\
\hline Germacreno D & 2,73 & & \\
\hline Curcumeno & & & 0,79 \\
\hline D-germacreno & & 0,79 & \\
\hline Cis- $\beta$-guaieno & & 1,06 & \\
\hline$\alpha$-zingibereno & & & 0,54 \\
\hline$\alpha$-selineno & & 0,45 & \\
\hline Biciclogermacreno & 1,05 & & \\
\hline$\alpha$-bisaboleno & & 17,19 & \\
\hline Cubebol & 0,22 & & \\
\hline$\beta$-sesquifelandreno & & 0,24 & \\
\hline Germacreno & 1,79 & & \\
\hline Espatulenol & 1,83 & 0,18 & \\
\hline Turmerol & & & 2,01 \\
\hline Óxido de cariofileno & 4,15 & 0,82 & \\
\hline Guaiol & 6,27 & & \\
\hline Diidroturmerona & & & 1,03 \\
\hline$\alpha$-acorenol & & & 0,63 \\
\hline$\beta$-acorenol & & & 0,38 \\
\hline Turmerona & & & 28,67 \\
\hline Bulnesol & 1,47 & & \\
\hline$\gamma$-z-atlantona & & & 26,10 \\
\hline 6S,7R-bisaboleno & & & 0,84 \\
\hline E-nuciferol & & & 0,91 \\
\hline$\alpha$-E-atlantona & & & 0,58 \\
\hline
\end{tabular}

Rendimento: ${ }^{\mathrm{a}} 2,0 \%,{ }^{\mathrm{b}} 0,69 \%,{ }^{\mathrm{c}} 1,47 \%$.

\section{CONCLUSÃO}

Foi possível investigar a atividade antibacteriana dos óleos essenciais de Aloysia gratissima (Gillies \& Hook) Tronc. (alfazema do Brasil), Ocimum gratissimum L. (alfavaca-cravo) e Curcuma longa L. (açafrão do Brasil) por meio da técnica de difusão em ágar utilizando discos de papel de filtro impregnados com os óleos essenciais das plantas estudadas. Os óleos essenciais apresentaram atividade inibidora de Staphylococcus aureus, porém apenas a alfavaca-cravo apresentou atividade sobre todas as cepas estudadas.

A utilização da bioautografia é de suma importância na avaliação da atividade antibacteriana de substâncias específicas presente nos óleos essenciais e extratos de plantas medicinais, pois na cromatografia em camada delgada (CCD) ocorre a separação de componentes bioativos presentes no óleo essencial e extratos e a atividade antimicrobiana de cada componente é avaliada individualmente, pela formação ou não de halos de inibição do crescimento bacteriano. Através do uso desta técnica para o óleo essencial de alfavaca-cravo, foi possível comprovar que o eugenol é a principal substância responsável pela atividade antibacteriana do mesmo. 
$\mathrm{Na}$ análise da composição química por CG-EM verificou-se a presença de $\beta$-pineno $(14,06 \%)$, transpinocanfona (18,42\%) e acetato de trans-pinocarvila (13,55\%) como majoritários no óleo essencial de Aloysia gratissima (Gill \& Hook) Tronc. e turmerona $(28,6 \%)$ e $\gamma$-z-atlantona $(26,10 \%)$ em Curcuma longa L. No óleo essencial de Ocimum gratissimum L. observou-se um predomínio de eugenol $(57,82 \%)$.

\section{REFERÊNCIAS BIBLIOGRÁFICAS:}

ADAMS, R. P. Identification of Essential Oil Components by Gas Chromatography/Mass Spectroscopy, $4^{\text {th }}$. ed. Carol Stream, IL, USA: Allured Publishing Corporation, 2007.

ADAMU, H.M.; ABAYED, O.J.; AGHO, M.O.; ABDULLAHI, A.L.; UBÁ, A.; DUKKU, H.U.; WUFEM, B.M. An ethnobotanical survey of Bauchi State herbal plants and their antimicrobial activity. Journal of Ethnopharmacology. v.99, n.1, p.1-4, 2005.

AGUIYI, J. C.; OBI, C. I.; GANG, S. S.; IGWEH, A. C. Hypoglycemic activity of Ocimum gratissimum in rats. Fitoterapia. v. 71, n. 4, p. 444-446, 2000.

AMARAL. M.F.Z.J..; BARA, M.T.F. Avaliação da atividade antifúngica de extratos de plantas sobre o crescimento de fitopatógenos. Revista Eletrônica de Farmácia. Suplemento v.2, n. 2, p. 5 - 8, 2005.

APISARIYAKUL, A; VANITTANAKOM, N.; BUDDHASUKH, D. Antifungal activity of turmeric oil extracted from Curcuma longa (Zingiberaceae). Journal of Ethnopharmacology. v. 49, n.3, p. 163-169, 1995.

AYISI, N. K.; NYADEDZOR, C..Comparative in vitro effects of AZT and extracts of Ocimum gratissimum, Ficus polita, Clausena anisata, Alchornea cordifolia and Elaeophorbia drupifera against HIV-1 and HIV-2 infections. Antiviral Research. v. 58, n.1, p.25-33, 2003.

ASHA, M.K., PRASHANTH, D.; MURALI, B.; PADMAJA, R.; AMIT, A. Anthelmintic activity of essencial oil of Ocimum sanctum and eugenol. Fitoterapia. v. 72, n. 6, p. 669-670, 2001.

BARA, M.T.F.; VANETTI, M.C.D. Antimicrobial Effect of Spices on the Growth of Yersinia enterocolitica. Jounal of Herbs, Spices and Medicinal Plants. v. 3, n. 4, p. 51-58, 1995.

BETINA, V. Bioautography in paper and thin-layer chromatography and its scope in the antibiotic field. Journal of Chromatography A. v. 78, p. 41-51, 1973.

BENENCIA, F.; COURRÈGES, M.C. In vitro and in vivo Activity of Eugenol on Human Herpesvirus. Phytoterapy Research. v. 14, n. 7, p.495-500, 2000.

BHAUMIK, S.; JYOTHI, M. D.; KHAR, A. Differential modulation of nitric oxide production by curcumin in host macrophages and NK cells. FEBS Letters, v. 483, n.2-3, p. 78-82, 2000.

BOSCÁ, A. R.; SOLER, A.; CARRIÓN-GUTIÉRREZ,M. A.; MIRA, D. P.; ZAPATA, J. P.; DIAZ-ALPERI, J.; BERND, A.; ALMAGRO, E. Q.; MIQUEL, J. A hydroalcoholic extract of Curcuma longa lowers the abnormally high values of human-plasma fibrinogen. Mechanisms of Ageing and Development. v.114, n. 3, p. 207-210, 2000.

BURT, S. Essential oils: their antibacterial properties and potencial applications in foods - a review, International Journal of Food Microbiology. v. 94, n.3, p. 223-253, 2004.

CARNOT, A.; CARNOT, A. P.; FRAISSE, D.; LAMAISON, J. L. The aromatic and polyphenolic composition of lemon verbena tea. Fitoterapia. v. 70, n.1, p. 44-49, 1999.

CECILIO FILHO, A. B.; SOUZA, R. J.; BRAZ, L. T.; TAVARES, M. Cúrcuma: planta medicinal, condimentar e de outros usos potenciais. Revista Ciência Rural. v. 30, n. 1, p. 171-175, 2000.

CECHINEL FILHO, V.; YUNES, R. A., Estratégias para obtenção de compostos farmacologicamente ativos a partir de plantas medicinais. Conceitos sobre modificação estrutural para otimização da atividade. Química Nova. v. 21, n. 1, p. 99105, 1998. 
CHAN, V. S.; CALDWELL, J. Comparative Induction of Unscheduled DNA Synthesis in Cultured Rat Hepatocytes by Allylbenzenes and their 1'-Hydroxy Metabolites. Food and Chemical Toxicology. v.30, n. 10, p. 831-836, 1992.

CHATTERJEE, S.; DESAI, S. R. P.; THOMAS P. Effect of $\gamma$-irradiation on the antioxidant activity of turmeric (Curcuma longa L.) extracts. Food Research International. v.. 32, n.7, p. 487-490, 1999.

CHUANG, S. E.; CHENG, A. L.; LIN, J. K.; KUO, M. L. Inhibition by curcumin of diethylnitrosamine-induced hepatic hyperplasia, inflammation, cellular gene products and cell-cycle-related proteins in rats. Food and Chemical Toxicology, v. 38, n. 11, p.991-995, 2000.

CORDO, H. A.; DELOACH, C. J. Natural Enemies of the Rangeland Weed Whitebrush (Aloysia gratissima: Verbenaceae) in South America: Potential for Biological Control in the United States. Biological Control, v. 5, n..2, p. 218-230, 1995.

DE, M.; DE, A.K.; BENERJEE, A.B. Antimicrobial Screening of Some Indian Spices. Phytoterapy Research. v. 13, n.7, p. 616-618, 1999.

DIDRY, N.; DUBREUIL, L.; PINKAS, M. New procedure for direct bioautographic TLC assay as applied to a tincture of Ranunculus bulbosus. Journal of Ethnopharmacology, v. 29, n.3, p. 283-290, 1990.

DOOL, H. V. D.; KRATZ, P. D. J. A. Generalization of the Retention Index System Including Linear Temperature Programmed Gas-Liquid Partition Chromatography, Journal of Chromatography A. v.11, p. 463-471, 1963.

DUBEY, N. K.; TIWARI, T. N.; MANDIN, D.; ANDRIAMBOAVONJY, H.; CHAUMONT, J. P. Antifungal properties of Ocimum gratissimum essential oil (ethyl cinnamate chemotype). Fitoterapia. v. 71, n. 5, p. 567-569,. 2000.

DUARTE, M.C.T.; LEME, E.E.; DELARMELINA, C.; SOARES, A.A.; FIGUEIRA, G.M.; SARTORATTO, A. Activity of essential oils from Brazilian medicinal plants on Escherichia coli. Journal of Ethnopharmacology. v.111, n.2, p. 197201.2007.

FARIA, T.J.; FERREIRA, R.S.; YASSUMOTO, L.; SOUZA, J.R.P.; ISHIKAWA, N.K.; BARBOSA, A.M. Antifungal activity of essential oil isolated from Ocimum gratissimum $L$. (eugenol chemotype) against phytopathogenic fungi. Brazilian Archives of Biology and Technology., v. 49, n. 6, p. 867-871, 2006.

GAYOSO, C.W. ; LIMA, B, E.O. ; OLIVEIRA, C, V.T. ; PEREIRA, F.O.; SOUZA, E.L.; LIMA, I.O. ; NAVARRO, D.F. Sensitivity of fungi isolated from onychomycosis to Eugenia cariophyllata essential oil and eugenol. Fitoterapia. v. 76, n.2, p. 247-249, 2005.

GOBB0-NETO, L.; LOPES, N.P. Fatores que interferem no teor de metabólitos secundários. Química Nova. v. 30, n. 2, p.374 - 381, 2007.

HAMBURGER, M. O.; CORDELL, G. A. A direct bioautographic TLC assay for compounds possessing antibacterial activity. Journal of Natural Products, v. 50, n. 1, p.19-22, 1987.

HARDMAN, J. G.; LIMBIRD, L. E.; GILMAN, A. G. Goodman \& Gilman: as bases farmacológicas da terapêutica. 10ª . ed. Rio de Janeiro: MacGraw-Hill, 2003.

HE, X. G.; LIN, L. Z.; LIAN, L. Z.; LINDENMAIER, M. Liquid chromatography-electrospray mass spestrometric analysis of curcuminoids and sesquiterpenoids in turmeric (Curcuma longa). Journal of Chromatography A. v. 800, n. 2, p.127132, 1998.

JIROVETZ, L.; BUCHBAUER, G.; SCHMIDT, E.; STOYANOVA, A.S; DENKOVA, Z.; NIKOLOVA, R.; GEISSLER, M. Purity, antimicrobial activities and olfactoric evaluations of geraniol/nerol and various of their derivatives. Journal of Essential Oil Research. v. 19, n. 3, p. 288-291, 2007. 
KÉITA, S. M.; VINCENT, C.; SCHMIT, J.; ARNASON, J. T.; BÉLANGER, A. Efficacy of Essential Oil of Ocimum basilicum L. and $O$. gratissimum L. Applied as an Insecticidal Fumigant and Powder to Control Callosobruchus maculatus (Fab.) [Coleoptera: Bruchidae]. Journal of Stored Products Research, v. 37, n. 4, p. 339-349, 2001.

KHAR, A.; MUBARAK ALI, A.; PARDHASARADHI, B. V. V.; BEGUM, Z.; ANJUM, R. Antitumor activity of curcumin is mediated through the induction of apoptosis in AK-5 tumor cells. FEBS Letters, v. 445, n. 1, p. 165-168, 1999.

KOEHN, F. E.; CARTER, G. T. The evolving role of natural products in drug discovery. Nature Reviews Drug Discovery, v.4, n.3, p.206-220, 2005.

KUMAR, S. R.; PILLAI, K. K.; BALANI, D. K.; HUSSAIN, S. Z. Antiatherosclerotic effect of Lipotab Forte in cholesterolfed rabbits. Journal of Ethnopharmacology. v. 59, n.3, p. 125-130, 1998.

LEE, H. S. Antiplatelet property of Curcuma longa L. rhizome-derived ar-turmerone. Bioresource Technology. v. 97, n. 12, p. 1372-1376, 2006.

LIMA, E. O.; GOMPERTZ, O. F.; PAULO, M. Q.; GIESBRECHT, A. M. In vitro antifungal activity of essential oils against clinical isolates of dermatophytes. Revista de Microbiologia, v. 23, n. 4, p. 235-238, 1992.

LUND, B. M.; LYON, G.D. Detection of inhibitors of Erwinia carotovora and E. Herbicola on thin-layer chromatograms. Journal of Chromatography A. v. 110, n. 1, p. 193-196, 1975.

MATOS, F. J. A. As plantas das farmácias vivas. Fortaleza: Imprensa Universitária UFC, 1997.

MATOS, F. J. A. Plantas medicinais: guia de seleção e emprego de plantas usadas em fitoterapia no Nordeste do Brasil. Fortaleza: imprensa universitária UFC, 2000. p. 157-158, 173-174.

NAKAMURA, C. V.; UEDA-NAKAMURA, T. ; BANDO, E.; MELO, A. F. N.; CORTEZ, D. A. G.; DIAS Fo, B. P. Antibacterial Activity of Ocimum gratissimum L. Essential Oil. Memórias do Instituto Oswaldo Cruz. v. 94, n. 5, p. 675$678,1999$.

OFFIAH, V. N.; CHIKWENDU, V. A. Antidiarrhoeal effects of Ocimum gratissimum leaf extract in experimental animals. Journal of Ethnopharmacology. v. 68, n. 1-3, p. 327-330, 1999.

ORAFIDIYA, L. O.; OYEDELE, A. O.; SHITTU, A. O.; ELUJOBA, A. A. The formulation of an Effective topical antibacterial product containing Ocimum gratissimum leaf essential oil. International Journal of Pharmaceutics. v. 224, n. 1-2, p. 177-183, 2001.

PAULA, J.A.M.; ROCHA, J.B.; NASCIMENTO, P.M.S.; REZENDE, M.H.; PAULA, J.R. Estudo farmacognóstico da casca de Pimenta pseudocaryophyllus (Gomes) L.R. Landrum - Myrtaceae. Revista Eletrônica de Farmácia. Suplemento v.3, n. 2, p. 01 - 03, 2006.

PERÉZ, G. S.; ZAVALA, S. M.; VARGAS, S. R.; PERÉZ, G. C.; PÉREZ, G. R. M. Antidiarrhoeal Activity of C-9 Aldehyde Isolated from Aloysia triphylla. Phytotherapy Research. v. 12, n. S1, p. S45-S46, 1998.

RAMìreZ-BOSCÁ, A.; SOLER, A; CARRIÓN, M. A.; DÍAZ-ALPERI, J.; BERND, A.; QUINTANILLA, C.; ALMAGRO, E. Q.; MIQUEL, J. A hydroalcoholic extract of Curcuma longa lowers the apo B/apo A ratio Implications for atherogenesis prevention. Mechanisms of Ageing and Development. v. 119, n.1-2, p. 41-47, 2000.

RAMÍREZ-TORTOSA, M. C.; MESA, M. D.; AGUILERA, M. C.; QUILES, J. L.; BARÓ, L.; RAMIREZ-TORTOSA, C. L.; MARTINEZ-VICTORIA, E.; GIL, A. Oral administration of a turmeric extract inhibits LDL oxidation and has hypocholesterolemic effects in rabbits with experimental atherosclerosis. Atherosclerosis. v. 147, n.2, p. 371-378, 1999.

SANTOS, S. C.; RIBEIRO, J. P.; GUIMARÃES, D. O.; SILVA, M. O.; FERRI, P. H.; GARCIA, A. C. F.; PIRES, J. S.; CASTROS, A. C. M.; SILVA, M. R. R.; PAULA, J. R. Antifungal activity of Eugenia uniflora L. fractions against Paracoccidiodes brasiliensis (Splendore) Almeida, Revista Brasileira de Plantas Medicinais. v. 7, n. 1, p. 30-33, 2004. 
SAXENA, G.; FARMER, S.; TOWERS, G. H. N.; HANCOCK,R. E. W. Use of specific dyes in the detection of antimicrobial compounds from crude plant extracts using a thin layer chromatography agar overlay technique. Phytochemical Analysis. v. 6, n.3, p. 125-129, 1995.

SILVA, M. G. V.; CRAVEIRO, A. A.; MATOS, F. J. A.; MACHADO, M. I. L.; ALENCAR, J. W. Chemical variation during daytime of constituents of the essential oil of Ocimum gratissimum leaves. Fitoterapia. v. 70, n.1, p. 32-34, 1999.

SILVA, J.; ABEBE, W.; SOUSA, S. M.; DUARTE, V. G.; MACHADO, M. I. L.; MATOS, E. T. A. Analgesic and antiinflammatory effects of essential oils of Eucalyptus. Journal of Ethnopharmacology. v. 89, n. 2, p. 277-283, 2003a.

SILVA, S. R. S.; DEMUNER, A. J.; BARBOSA, L. C. A.; ANDRADE, N. J.; NASCIMENTO, E. A.; PINHEIRO, A. J. Análise de constituintes químicos e da atividade antimicrobiana do óleo essencial de Melaleuca alternifolia Cheel, Revista Brasileira de Plantas Medicinais. v. 6, n. 1, p. 63-70, 2003b.

SINGHAL, S. S.; AWASTHI, S.; PANDYA, U.; PIPER, J. T.; SAINI, M. K.; CHENG, J. Z.; AWASTHI, Y. C. The effect of curcumin on glutathione-linked enzymes in K562 human leukemia cells. Toxicology Letters. v. 109, n. Supp.1, p. 8795, 1999.

SOLER, E.; DELLACASSA, E.; MOYNA, P. Composition of Aloysia gratissima leaf essential oil. Phytochemistry. v. 25, n. 6 , p. $1343-1345,1986$.

SOUZA, C. R. A.; GLÓRIA, M. B. A. Chemical analysis of turmeric from Minas Gerais, Brazil and comparison of methods for flavour free oleoresin. Brazilian Archives of Biology and Technology. v. 41, n. 2, p. 218-224, 1998.

TAVARES, W. Manual de antibióticos e quimioterápicos antiinfecciosos. 3. ed. São Paulo. Atheneu, 2001.

UEDA-NAKAMURA, T.; MENDONÇA-FILHO, R.R.; MORGADO-DIAZ, J.A.; MAZA, P. K.; FILHO, B. P. D.; CORTEZ, D. A.G.; ALVIANO, D. S.; ROSA, M. S. S.; LOPES, A. H. C. S.; ALVIANO. C. S.; NAKAMURA C. V. Antileishmanial activity of Eugenol-rich essential oil from Ocimum gratissimum. Parasitology International. v. 55, n.2, p. 99 - 105. 2006.

VIEIRA, R. F.; GRAYER, R. J.; PATON, A.; SIMON, J. E. Genetic diversity of Ocimum gratissimum L. based on volatile oil constituents, flavonoids and RAPD markers. Biochemical Systematics and Ecology, v. 29, n. 3, p. 287-304, 2001.

VINCENZI, M.; SILANO, M.; MAIALETTI, F.; SCAZZOCCHIO, B. Constituents of aromatic plants: II. Estragole. Fitoterapia, v. 71, n. 6, p. 725-729, 2000.

XIA, X.; CHENG, G.; PANA, Y.; XIA, Z. H.; KONG, L.D. Behavioral, neurochemical and neuroendocrine effects of the ethanolic extract from Curcuma longa $L$. in the mouse forced swimming test. Journal of Ethnopharmacology. v. 110, $n$. 2, p. 356-363. 2007.

YUNES, R. A.; PEDROSA, R. C.; CECHINEL FILHO, V., Fármacos e fitoterápicos: A necessidade do desenvolvimento de fitoterápicos e fitofármacos no Brasil. Química Nova. v. 24, n. 1, p. 147-152, 2001. 